\title{
Synthesis and characterization of a novel temperature-pH responsive copolymer of 2 -hydroxypropyl acrylate and aminoethyl methacrylate hydrochloric salt
}

\author{
K. L. Deng*, H. Tian, P. F. Zhang, X. B. Ren, H. B. Zhong \\ College of Chemistry \& Environmental Science, Hebei University, Baoding 071002, China
}

Received 23 November 2008; accepted in revised form 4 January 2009

\begin{abstract}
In this investigation, a novel temperature-pH responsive copolymer was prepared by the radical copolymerization between 2-hydroxypropyl acrylate (HPA) and aminoethyl methacrylate hydrochloric salt (AMHS). The molecular structure of the corresponding copolymer has been confirmed by ${ }^{1} \mathrm{H}$ NMR and FTIR measurements. The results indicated that the lower critical solution temperature (LCST) of the resulting copolymer has shown a considerable dependence on the monomer ratio and $\mathrm{pH}$ value in the medium. When the molar ratio of HPA to AMHS unit on polymer chain was fixed at 1.56, 2.25, and 3.01, the LCSTs of copolymers were observed at 36.5, 28.2 and $17.8^{\circ} \mathrm{C}$, respectively. For the effect of additive salts, the LCST change of the copolymer was affected by both cations and anions in the following order of $\mathrm{Al}\left(\mathrm{NO}_{3}\right)_{3}>$ $\mathrm{KNO}_{3}>\mathrm{Mg}\left(\mathrm{NO}_{3}\right)_{2}>\mathrm{NaNO}_{3}$ and $\mathrm{KCl} \approx \mathrm{KSCN}>\mathrm{KBr}>\mathrm{KNO}_{3}>\mathrm{KI}$. The copolymer seems to be useful as a candidate for the controlled-drug release carrier by $\mathrm{pH}$ and temperature external stimuli.
\end{abstract}

Keywords: smart polymers, temperature-pH responsive polymer, lower critical solution temperature

\section{Introduction}

In recent years, the responsive polymers have attracted considerable interest for their chemical or physical property changes in response to the external stimuli such as temperature, $\mathrm{pH}$, specific ions, and electric field [1]. As the important responsive polymers, the temperature or $\mathrm{pH}$-responsive polymers are widely applied in many fields including drug-delivery system [2], chemical separation [3], and gene carriers [4].

The thermo-sensitive polymers reversibly become a uniform sphere from a random coil chain in the solution at a certain temperature, namely, the lower critical solution temperature (LCST) [5]. These phenomena can also be observed when other external parameters are changed such as $\mathrm{pH}$ value [6], electric field [7], and ionic strength [8]. Normally, the LCST value of polymer is greatly affected by the balance of the hydrophilic and hydrophobic groups in the polymer. In other words, the hydrophilic and hydrophobic interactions between the polymer chains play a significant role in determining their LCST value. The two interactions in nature are related to the hydrophobic interaction among polymers and to hydrophilic interaction (hydrogen bonding) between hydrophilic groups of polymer and water molecules. If the excessively hydrophilic or hydrophobic groups are attached to the polymer backbone, no thermo-sensitivities of the polymers are observed under common conditions. It has been reported that the change of hydrophilic/hydrophobic groups on the macromolecular chains leads to several thermo-sensitive polymers with different LCST values. Such poly- 
mers include $\operatorname{poly}(N, N$ '-diethyl acrylamide) [1], poly( $N$-isopropylacrylamide) [9], poly(2-isopropyl2-oxazoline) [10], and poly(vinyl methyl ether) [11] and so on. For example, Schild [12] reported that the LCST of a thermo-responsive polymer containing $\mathrm{N}$-isopropylacrylamide was controlled by the content of hydrophilic amide groups and hydrophobic groups. In addition, in order to get polymers with much better controlled temperatureresponsive properties, some copolymers were synthesized by the introduction of other monomers or natural polymers. The various copolymers were prepared to meet the demands in many fields, such as poly $(\mathrm{N}$-isopropylacrylamide- $\mathrm{Co}$-acrylamide- $\mathrm{Co}$ hydroxyethylmethacrylate) [13], poly ( $N, N$-dimethylacrylamide- $b-N$-isopropylacrylamide- $b$ - $N$-acryloylvaline) [14], poly( $N$-isopropylacrylamide/carboxymethyl chitosan) [15], and poly( $N$-isopropylacrylamide-co-diethyleneglycol methacrylate) [16].

2-Hydroxypropyl acrylate (HPA) is extensively applied in fibre, adhesives, rubber industry, paints and coatings industry [17]. To the best of our knowledge, the preparation of the copolymer between HPA and AMHS as a temperature-responsive material has not been reported in the literature. By varying the monomer ratio in the copolymerization of HPA and AMHS, the balance between hydrophobicity and hydrophilicity on the copolymer chain can be effectively controlled to some extent. Accordingly, HPA/AMHS copolymer may theoretically exhibit a reversible temperatureresponsive property. The incorporation of AMHS into the macromolecular chain may produce a $\mathrm{pH}$ responsive copolymer, because AMHS is a kind of weak-base/strong-acid salt. The copolymer also responds to inorganic ion stimuli and shows a phase transition.

The aim of this study was to prepare a novel copolymer of HPA and AMHS and evaluate the dual responsiveness (temperature and $\mathrm{pH}$ ) in its aqueous solution. The molecular structure of the resulting copolymer and the monomer was characterized by ${ }^{1} \mathrm{H}$ NMR and FTIR measurements. By varying the ratio of HPA to AMHS, the hydrophilic and hydrophobic balance of the resulting copolymer was adjusted effectively. When the molar ratio of HPA to AMHS unit on polymer chain was fixed at 1.56, 2.25, and 3.01, the LCSTs of copolymers in the aqueous solution were found to be $36.5,28.2$ and $17.8^{\circ} \mathrm{C}$, respectively. Furthermore, a series of inorganic salts were selected to evaluate the salt effect on LCST of the resulting copolymer.

\section{Experimental section}

\subsection{Materials}

2-aminoethanol, propylene oxide and benzoyl chloride were purchased from Dongfang health materials factory (Tianjin, China) and Huadong Chemical Factory (Tianjin, China), respectively. Acrylic acid and methacrylic acid were purified by vacuum distillation. Potassium persulfate (KPS) was recrystallized from deionized water before used. The other solvents were analytical grade and used without any further purification.

\subsection{Measurements}

Fourier-transform infrared spectra (FTIR) of the monomer and the corresponding copolymers were recorded on a Vector22 FT-IR spectrophotometer with $\mathrm{KBr}$ pellet in the range of $400-4000 \mathrm{~cm}^{-1}$. ${ }^{1} \mathrm{H}$ NMR spectra were measured with a Bruker Avance-400 (400 MHz) using $\mathrm{D}_{2} \mathrm{O}$ as solvent and TMS as internal standard. The thermo-sensitivities of the copolymer in the solution were detected by monitoring the optical transmittance at $500 \mathrm{~nm}$ on a Shimadzu UV-120-02 spectrophotometer with a thermally-controlled cuvette holder. The heating rate was controlled at $0.5^{\circ} \mathrm{C} / \mathrm{min}$ in our experiment. The temperature at which the transmittance of the copolymer solution decreased to half of the initial value during heating was defined as LCST for the copolymers in our study.

\subsection{Synthesis of HPA and AMHS}

2 -aminoethanol hydrochloride was prepared via the neutralization of 2-aminoethanol with the calculated amount of hydrochloride solution and complete drying under vacuum at $70^{\circ} \mathrm{C}$. Methacryloyl chloride was synthesized by reacting methacrylic acid with benzoyl chloride according to the literature [18]. The mixture of 2-aminoethanol hydrochloride and methacryloyl chloride with an excess of $10 \%$ was heated up to $75^{\circ} \mathrm{C}$ and the temperature was maintained for $2 \mathrm{~h}$. Then, it was cooled and dissolved in tetrahydrofuran. The solution of the crude AMHS was poured into ethyl ether to remove the un-reacted methacryloyl chloride. The pure 
AMHS, a white powder, was obtained after filtration with a yield of $81 \%$.

FTIR [ $\mathrm{cm}^{-1}$ ] for AMHS: 3381, 3044 (broad $\left.v_{\mathrm{N}-\mathrm{H}}\right)$, 2974-2887 (strong $v_{\mathrm{C}-\mathrm{H}}$ ), 1720 (strong $v_{\mathrm{C}=\mathrm{O}}$ ), 1622 (weak $v_{-\mathrm{C}=\mathrm{C}-}$ ), 1494 (median $\left.\delta_{\mathrm{N}-\mathrm{H}}\right), 1064$ (strong

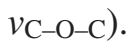

$0.28 \mathrm{~mol}$ propylene oxide, $0.2 \mathrm{~mol}$ acrylic acid, a trace amount of $\mathrm{CuCl}$ as inhibitor and pyridine as catalyst were added into the round flask with a condenser. The mixture was heated to $90^{\circ} \mathrm{C}$ and kept for $4 \mathrm{~h}$. Finally, the isomers (HPA) containing 2hydroxypropyl acrylate and 2-hydroxyisopropyl acrylate were obtained after vacuum distillation with a yield of $63 \%$. From ${ }^{1} \mathrm{H}$ NMR measurement, HPA was composed of pure 2-hydroxypropyl acrylate and 2-hydroxyisopropyl acrylate, and the molar ratio of two isomers was about 1.7:1.

FTIR $\left[\mathrm{cm}^{-1}\right]$ for HPA: 3420 (broad $v_{\mathrm{O}-\mathrm{H}}$ ), 2977-2885 (strong $v_{\mathrm{C}-\mathrm{H}}$ ), 1720 (strong $v_{\mathrm{C}=\mathrm{O}}$ ), 1617 (weak $v_{-\mathrm{C}=\mathrm{C}-}$ ), 1194 (strong $v_{\mathrm{O}-\mathrm{C}=\mathrm{O}}$ ), 1080 (strong

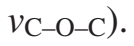

\subsection{Synthesis of the copolymers from HPA and AMHS}

A series of the copolymers with various feed ratios of HPA to AMHS were synthesized by the conventional radical copolymerization using $\mathrm{K}_{2} \mathrm{~S}_{2} \mathrm{O}_{8}$ $\mathrm{NaHSO}_{3}$ as the redox initiator. In the polymerization, the molar ratio of monomers to initiator was fixed at 100:1 and the total monomer concentration was $0.3 \mathrm{~mol} / \mathrm{l}$ in the deionized water. The Schlenk tube was added with the required amount of $\mathrm{K}_{2} \mathrm{~S}_{2} \mathrm{O}_{8}-\mathrm{NaHSO}_{3}$ initiator, HPA, AMHS and deionized water. After degassing with dry nitrogen, the reaction mixture was magnetically stirred for $10 \mathrm{~h}$ at room temperature. Finally, the resulting mixture was precipitated into cold sodium chloride solution to remove the residual HPA, AMHS and un-reacted initiator. After several washing with hot water, the title copolymer was obtained via filtration and dried under vacuum at $60^{\circ} \mathrm{C}$ for $48 \mathrm{~h}$. When the ratio of HPA to AMHS was fixed at 1, 2, 3 and 4 in the copolymerization, the corresponding copolymers were designated as PHA1, PHA2, PHA3, and PHA4. From ${ }^{1} \mathrm{H}$ NMR measurements, The molar ratio of HPA to AMHS on polymer chain for PHA1, PHA2, PHA3, and PHA4 were 0.75:1, 1.56:1, 2.25:1 and 3.01:1, respectively.

\section{Results and discussion}

\subsection{Molecular design for the temperature-pH sensitive polymers}

The synthetic route for the copolymer studied in this paper is shown in Figure 1. We firstly prepared nonionic HPA and ionic AMHS monomer. The temperature-pH responsive copolymer of two monomers was obtained by solution polymerization initiated with $\mathrm{K}_{2} \mathrm{~S}_{2} \mathrm{O}_{8}-\mathrm{NaHSO}_{3}$. Herein, the HPA monomer units on the copolymer chains serve as the hydrophobic moieties and AMHS units function as the hydrophilic groups. The modulation of hydrophobicity and hydrophilicity on the polymer

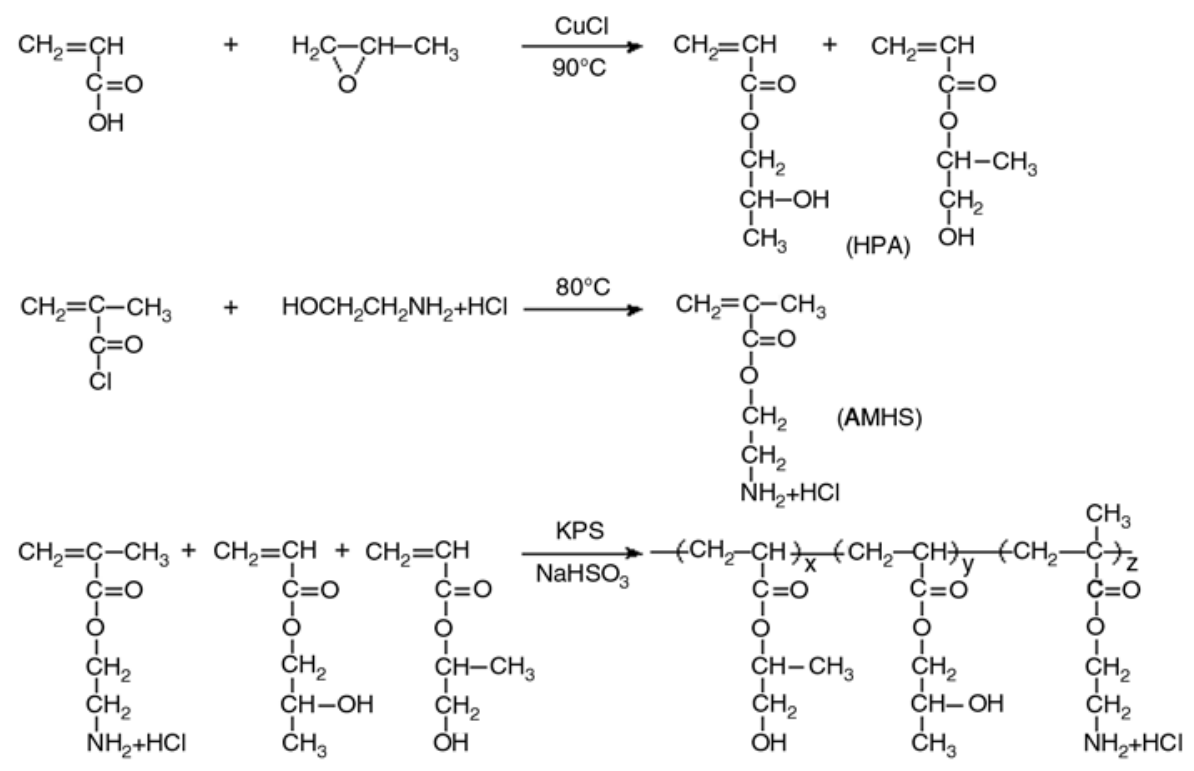

Figure 1. Synthetic route for the temperature-pH sensitive polymer 
chains was achieved via changing the ratio of HPA to AMHS in the polymerization. It was found that only the corresponding copolymers with given monomer ratio did show a reversible thermo-sensitiveness. In contrast with this result, no LCST was observed in the aqueous solutions of poly(AMHS). The reason is attributed to the following fact that too high hydrophilic interactions allow the homopolymer of AMHS to completely dissolve in water. Accordingly, the appropriate balance between hydrophobicity and hydrophilicity on the polymer chains plays a crucial role in preparation of thermo-responsive polymer.

\subsection{Structural confirmation of the copolymer from HPA and AMHS}

The FTIR spectrum and the ${ }^{1} \mathrm{H}$ NMR spectrum of PHA4 were recorded in order to confirm the structure of the copolymer. As shown in Figure 2 of PHA4 FTIR spectrum, the broad peaks from about 3600 to $3250 \mathrm{~cm}^{-1}$ suggested the presence of the $-\mathrm{OH}$ and $-\mathrm{NH}_{2} \cdot \mathrm{HCl}$ groups. The strong characteristic absorption at $1735.8 \mathrm{~cm}^{-1}$ was observed, which was ascribed to the characteristics stretching vibration of $\mathrm{C}=\mathrm{O}$ group from HPA and $\mathrm{AMHS}$ repeating units. Also, the absorption bands at $1176.2 \mathrm{~cm}^{-1}$ could be attributed to the $\mathrm{C}-\mathrm{O}-\mathrm{C}$ stretching vibration. In the ${ }^{1} \mathrm{H}$ NMR spectrum of PHA4 shown in Figure 3, the main peaks of the copolymer PHA4 were found. For example, the peaks at 4.06 and $3.61 \mathrm{ppm}$ were ascribed to methylene and methine groups in $\left[-\mathrm{OC}_{2} \underline{\mathrm{C}}_{\underline{H}}(\mathrm{OH}) \mathrm{CH}_{3}\right]$ repeating unit. The chemical shift of methylene and methine groups in $\left[-\mathrm{OC}_{2} \underline{\mathrm{H}}_{2} \mathrm{C} \underline{\mathrm{H}}(\mathrm{OH}) \mathrm{CH}_{3}\right]$ repeating unit was also observed at 3.61 and $4.06 \mathrm{ppm}$. The peaks for the two methylene groups $\left[-\mathrm{OC} \underline{H}_{2} \underline{\mathrm{C}}_{2} \mathrm{NH}_{2} \cdot \mathrm{HCl}\right]$ in AMHS unit were recorded at 4.21 and 3.32 ppm respectively. Here, the peak at $4.9 \mathrm{ppm}$ possibly indicated the existence of $-\mathrm{NH}_{2}$ groups in the AMHS repeating unit. It is necessary to state that no peaks for $-\mathrm{OH}$ group were found in the measurement using $\mathrm{D}_{2} \mathrm{O}$ as solvent. The above-mentioned spectral data confirmed the structure of the target copolymer. In addition, the molar ratio of HPA to AMHS on polymer chain for PHA1, PHA2, PHA3, and PHA4 were found to be $0.75: 1,1.56: 1,2.25: 1$ and 3.01:1, respectively, from ${ }^{1} \mathrm{H}$ NMR results.

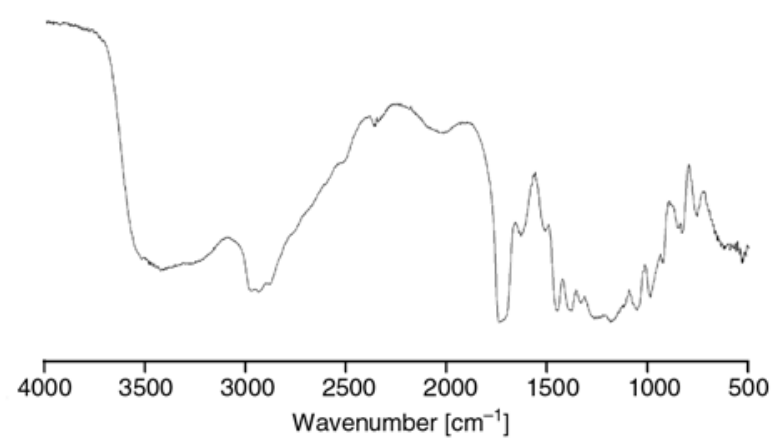

Figure 2. FTIR spectrum of the PHA4

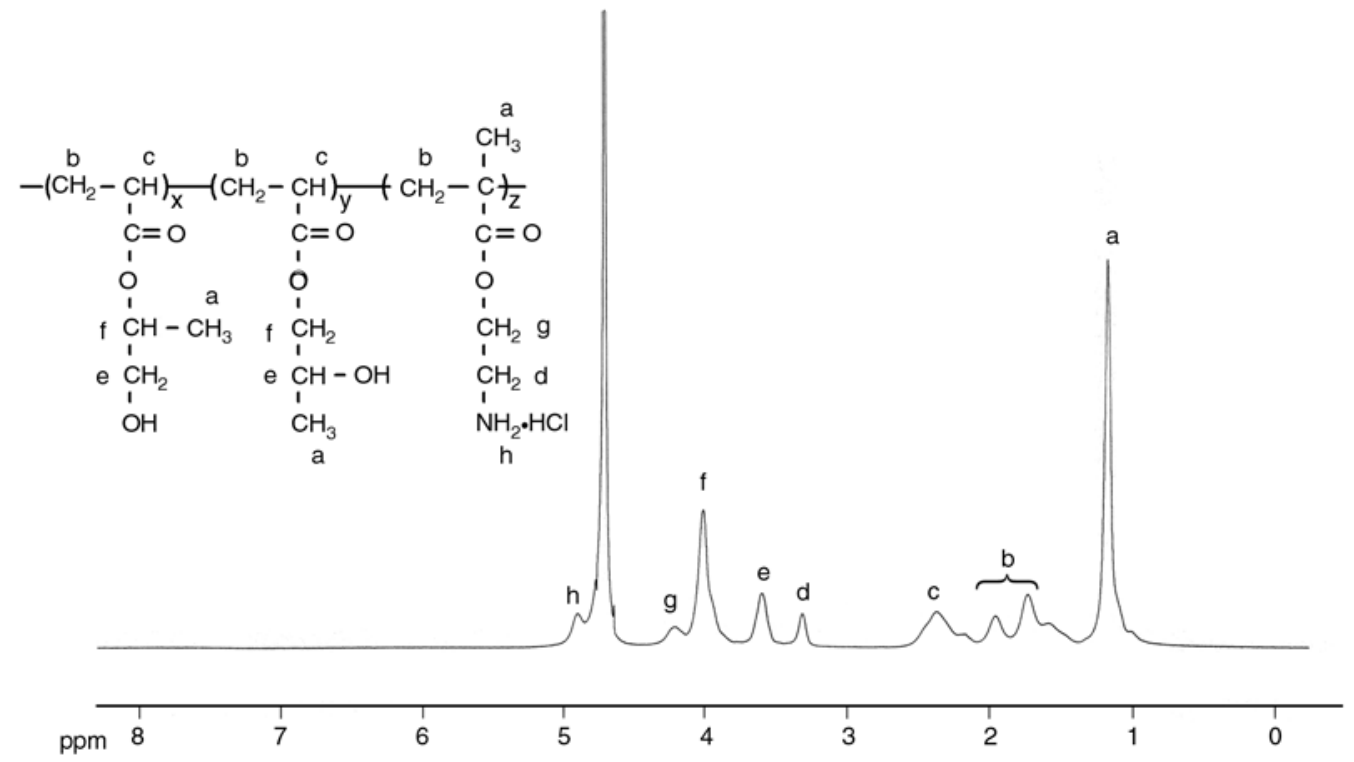

Figure 3. ${ }^{1} \mathrm{H}$ NMR spectrum of the PHA4 


\subsection{Effect of the different factors on LCST}

\subsubsection{Effect of copolymer concentration in aqueous solution on LCST}

In this study, the temperature at which the transmittance decreased to half of the initial value was defined as the LCST. For the thermo-sensitive polymer, a clear aqueous copolymer solution below LCST became cloudy upon heating. A typical optical transmittance of the solution of PHA3 as a function of temperature is shown in Figure 4. Clearly, the PHA3 precipitated out from the aqueous solution at temperature around $25-45^{\circ} \mathrm{C}$ range, depending on its concentration. The LCST value decreased as the polymer concentration increased. When PHA3 concentration was $1 \mathrm{wt} \%$, its LCST was about $40^{\circ} \mathrm{C}$. As PHA3 concentration was increased to 2 and $3 \mathrm{wt} \%$, the LCSTs of PHA3 reached about 28.2 and $30.1^{\circ} \mathrm{C}$, respectively. This result shows no remarkable dependence of LCST upon the concentration values at higher copolymer concentration. Additionally, the phase transition interval is more than $10^{\circ} \mathrm{C}$ for PHA3 copolymers. The reason for this observation can be probably ascribed to the wider molecular weight distribution of copolymer or the different sequence of the monomer unit on copolymer chain. The wider phase transition temperature was also reported in another copolymer system from 2-hydroxylpropyl acrylate [19].

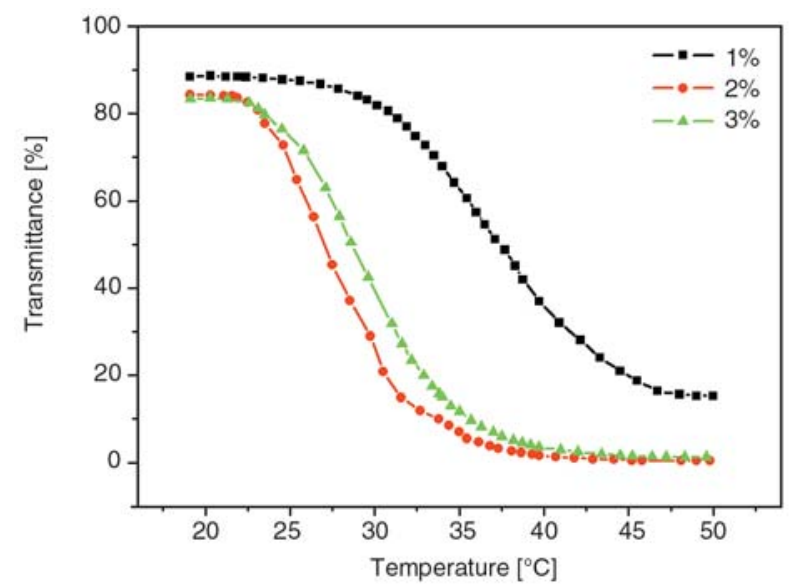

Figure 4. Effect of the copolymer concentration in aqueous solution on LCST Solvent: deionized water; $\mathrm{pH}=6.5$; wavelength $=500 \mathrm{~nm}$

\subsubsection{Effect of the ratio of HPA to AMHS on LCST}

The temperature-responsiveness of the title copolymers was confirmed by monitoring transmittance in

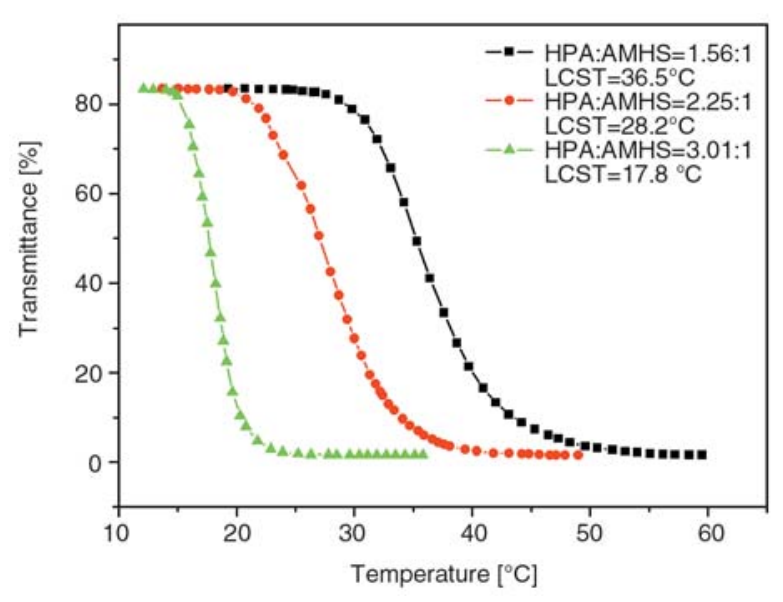

Figure 5. Transmittance as a function of temperature for copolymer in aqueous solution Solvent: deionized water; $\mathrm{pH}=6.5$; wavelength $=500 \mathrm{~nm}$

$3 \%(w t)$ solution as a function of temperature. As shown in Figure 5, the LCST of copolymer were $36.5,28.2$ and $17.8^{\circ} \mathrm{C}$, respectively, when the molar ratios of HPA to AMHS on polymer chain were fixed at 1.56, 2.25 and 3.01. This result suggested that LCST of copolymer was decreased with increasing content of hydrophoblic HPA units. Compared to AMHS, HPA factually exhibits a slight hydrophobicity to some extent. The similar tendency has been reported that the LCST of $\mathrm{N}$-isopropylacrylamides-based copolymer was decreased by the incorporation of more hydrophobic monomer [20]. Additionally, no obvious LCSTs were observed in the copolymer aqueous solution when the ratio of HPA to AMHS was under 1 or above 5 in the copolymerization. The reasons for this may be explained as the excessive hydrophilicity or hydrophobicity in the copolymeric chains. LCST values of the copolymers prepared in this study, especially for PHA2, are very close to the physiological temperature. As a result, these copolymers are suitable to the application in the biomedical fields. In addition, the more sensitive responsiveness was found with increasing the hydrophobic HPA unit content in copolymer chains. The temperature span in the phase transition for PHA2 was about $28^{\circ} \mathrm{C}$ (from 27 to $55^{\circ} \mathrm{C}$ ), whereas the range during the phase transition for PHA4 reached about $12^{\circ} \mathrm{C}$ (from 13 to $25^{\circ} \mathrm{C}$ ).

\subsubsection{Effect of pH value on LCST}

Figure 6 demonstrates the effect of $\mathrm{pH}$ on LCST of PHA3 copolymer. Herein, the phosphate buffered 


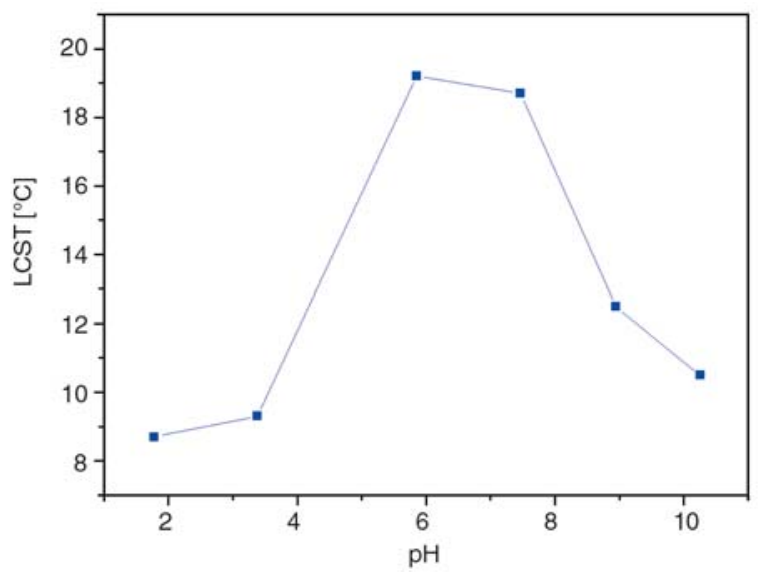

Figure 6. Effect of $\mathrm{pH}$ in copolymers aqueous solution on LCST Solvent: phosphate buffered saline (PBS); wavelength $=500 \mathrm{~nm}$

saline (PBS) with the same ion strength $(I=0.6)$ was used as the medium for the different $\mathrm{pH}$. From the figure it is seen that the phase transition behavior is considerably dependent on the $\mathrm{pH}$ value in the solution; increasing $\mathrm{pH}$ leads to higher LCST value in the range of $\mathrm{pH} 1.78-5.85$. This effect is related to the dissociative behaviors of the aminoethyl hydrochloric salt moiety on AMHS units. The ionization degree of aminoethyl hydrochloric salt was increased with increasing $\mathrm{pH}$ value due to its weakbase/strong-acid salt nature. So, the hydrophilicity of copolymer increases with $\mathrm{pH}$ value, resulting in a higher LCST value. This result is consistent with the reported phase transition behaviors of $\operatorname{poly}(N$, $\mathrm{N}$-diethylacrylamide-co-methacrylic acid) in different $\mathrm{pH}$ solution [21]. At too higher $\mathrm{pH}$, however, the LCST sharply decreased with increasing $\mathrm{pH}$ value. For instance, when $\mathrm{pH}$ values were adjusted to $7.46,8.94$ and 10.25 , the LCSTs were $18.7,12.5$ and $10.5^{\circ} \mathrm{C}$, respectively.

\subsubsection{Effect of the additive salt on LCST of the copolymer}

The thermo-sensitiveness of the copolymers is derived from the hydrophilic/hydrophobic interactions related to the copolymer chains and water molecules [22]. The existence of some amino salt groups on the copolymers prepared from HPA and AMHS may likely alter the aforementioned interaction, further inducing a change of LCST value. Some salts increase the LCST of polymers, which is called the 'salting-in' effect; while other salts can decrease the LCST value, which is called 'salting- out' effect [23]. In order to investigate the effect of some inorganic salts on LCST of the copolymer, two series of potassium salt and metallic nitrate $(0.02-0.20 \mathrm{~mol} / \mathrm{l})$ were added into the copolymer aqueous solution ( $3 \mathrm{wt} \%$ ), and their LCSTs were measured.

Figure 7 has shown the LCST-shifting effect with respect to the concentration of potassium salts. Clearly, the LCST value of copolymer PHA4 changed drastically when potassium salts was charged to copolymer solution. The changing LCST increased with increasing its concentration. For example, when the concentration of $\mathrm{KBr}$ was $0.02,0.05,0.10,0.15$, and $0.20 \mathrm{~mol} / \mathrm{l}$, the LCST of PHA4 changed to $16.4,15.8,15.2,14.9$ and $14.4^{\circ} \mathrm{C}$ from $17.8^{\circ} \mathrm{C}$ (in deionized water). The result was in a good agreement with the studies on aqueous hydroxypropyl cellulose solution by Oshima and co-workers [24]. In addition, different from the effect of $\mathrm{KBr}$ and $\mathrm{KCl}$, LCST of the copolymer PHA4 exhibited an increasing tendency with increasing the concentration of KI. The LCSTs of PHA4 increased to $18.1,18.0,18.5,19.5$ and $20.6^{\circ} \mathrm{C}$, respectively, as $\mathrm{KI}$ concentrations were fixed at $0.02,0.05,0.10,0.15,0.20 \mathrm{~mol} / \mathrm{l}$. It has generally been accepted that the larger anion such as I' $^{-}$served as 'salting-in' effect, while the smaller anion including $\mathrm{F}^{-}, \mathrm{Br}^{-}$and $\mathrm{Cl}^{-}$functioned as 'salting-out' effect [23]. From the comparative data of three anions, the effectiveness order from 'saltingout' to 'salting-in' in this system is summarized as follows: $\mathrm{KCl} \approx \mathrm{KSCN}>\mathrm{KBr}>\mathrm{KNO}_{3}>\mathrm{KI}$. The experiment result is consistent with the investigation on the other polymer system [25]. In overall,

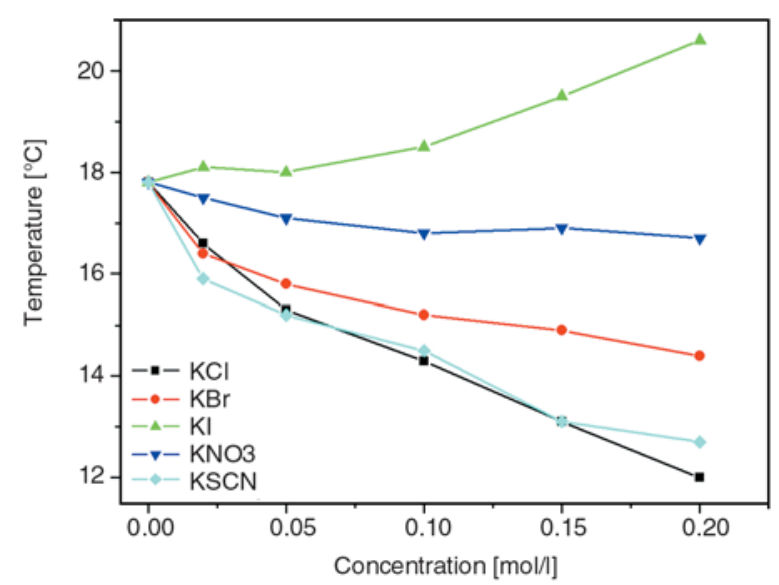

Figure 7. Effect of a series of potassium salts in PHA4 aqueous solution on LCST Solvent: deionized water; wavelength $=500 \mathrm{~nm}$ 
KI seems to increase $\mathrm{H}$-bonding (hydrophilic interaction) between water molecules and copolymer chains, leading to an increase in LCST value. On the contrary, $\mathrm{KBr}$ and $\mathrm{KCl}$ seem to decrease the interaction among water and polymer, resulting in decrease of the LCST.

Figure 8 illustrated the effect of several metallic nitrates on the LCST of copolymers as function of its concentration. The addition of metallic nitrate into the aqueous copolymer solution also induced the alteration of LCST, especially for $\mathrm{NaNO}_{3}$, $\mathrm{Mg}\left(\mathrm{NO}_{3}\right)_{2}$ and $\mathrm{KNO}_{3}$. For instance, when the concentrations of $\mathrm{NaNO}_{3}$ and $\mathrm{Mg}\left(\mathrm{NO}_{3}\right)_{2}$ were controlled at $0.20 \mathrm{~mol} / \mathrm{l}$, the change of LCST was found to be $4.9^{\circ} \mathrm{C}\left(12.9-17.8^{\circ} \mathrm{C}\right)$ and $2.0^{\circ} \mathrm{C}(15.8$ $\left.-17.8^{\circ} \mathrm{C}\right)$, respectively. $\mathrm{Al}\left(\mathrm{NO}_{3}\right)_{3}$, however, appears to be a weak LCST-shifter in our system, which is not in accordance with the study on hydroxypropyl cellulose system by Oshima [24]. The reason may likely be ascribed to the fact that the copolymer with amino salts investigated in this paper is different from the nonionic hydroxypropyl cellulose studied by Oshima. Additionally, $\mathrm{NO}_{3}^{-}$ions act as LCST-elevating driver. The LCST-elevating potential from $\mathrm{NO}_{3}^{-}$ions in $\mathrm{Al}\left(\mathrm{NO}_{3}\right)_{3}$, solution overtakes that in $\mathrm{NaNO}_{3}, \mathrm{Mg}\left(\mathrm{NO}_{3}\right)_{2}$ and $\mathrm{KNO}_{3}$ solution with the same molar concentration. Concerning the overall effect of nitrates selected, it could be concluded that the order in effectiveness from 'saltingin' to 'salting-out' was $\mathrm{Al}\left(\mathrm{NO}_{3}\right)_{3}>\mathrm{KNO}_{3}>$ $\mathrm{Mg}\left(\mathrm{NO}_{3}\right)_{2}>\mathrm{NaNO}_{3}$. Therefore, $\mathrm{NaNO}_{3}$ could be used as the efficient LCST-shifter for this copolymer from HPA and AMHS.

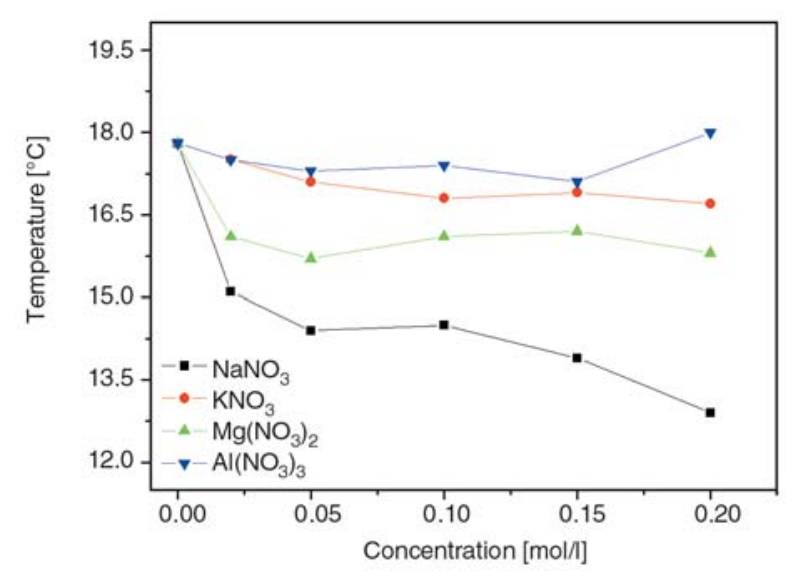

Figure 8. Effect of a series of metallic nitrates in PHA4 aqueous solution on LCST Solvent: deionized water; wavelength $=500 \mathrm{~nm}$

\section{Conclusions}

In this study, a novel $\mathrm{pH}$-temperature responsive copolymers were prepared by modulating the ratio of HPA to AMHS monomers. The LCSTs of the resulting copolymers rapidly increased as the content of hydrophilic monomer AMHS was increased. Also, the copolymer exhibited a complicated phase transition behavior in the different $\mathrm{pH}$ medium, i.e., its LCST first increased and thereafter decreased with an increase in $\mathrm{pH}$ value. The investigation on the effect of additive salts suggested that LCST of copolymer shifted either down or up, depending on the different cations and anions, as well as on their concentration. These copolymers seem to be good candidates for being used as controlled-drug release carriers by $\mathrm{pH}$ and temperature stimuli.

\section{Acknowledgements}

The authors are grateful for financial support from the Hebei Natural Science Foundation of China (B2008000573).

\section{References}

[1] Gil E. S., Hudson M. S.: Stimuli-reponsive polymers and their bioconjugates. Progress in Polymer Science, 29, 1173-1222 (2004). DOI: 10.1016/j.progpolymsci.2004.08.003

[2] Zhang J-T., Xue Y-N., Gao F-Z., Huang S-W., Zhou R-X.: Preparation of temperature-sensitive $\operatorname{poly}(N$ isopropylacrylamide)/ $\beta$-cyclodextrin-grafted polyethylenimine hydrogels for drug delivery. Journal of Applied Polymer Science, 108, 3031-3037 (2008). DOI: 10.1002/app.27931

[3] Kanazawa H., Sunamoto T., Matsushima Y., Kikuchi A., Okano T.: Temperature-responsive chromatographic separation of amino acid phenylthiohydantoins using aqueous media as the mobile phase. Analytical Chemistry, 72, 5961-5966 (2008). DOI: $10.1021 / \mathrm{ac0004658}$

[4] Kurisawa M., Yokoyama M., Okano T.: Gene expression control by temperature with thermo-responsive polymeric gene carriers. Journal of Controlled Release, 69, 127-137 (2000).

DOI: $10.1016 / \mathrm{S} 0168-3659(00) 00297-2$

[5] Washington R. P., Steinbock O.: Frontal polymerization synthesis of temperature-sensitive hydrogels. Journal of the American Chemical Society, 123, 7933-7934 (2001). DOI: $\underline{10.1021 / \mathrm{ja} 0161103}$ 
[6] Zhang J., Peppas N. A.: Synthesis and characterization of $\mathrm{pH}$ - and temperature-sensitive poly(methacrylic acid)/poly( $N$-isopropylacrylamide $)$ interpenetrating polymeric networks. Macromolecules, 33, 102-107 (2000).

DOI: $10.1021 / \mathrm{ma} 991398 \mathrm{q}$

[7] Li H., Chen J., Lam K. Y.: Multiphysical modeling and meshless simulation of electric- sensitive hydrogels. Journal of Polymer Science Part B: Polymer Physics, 42, 1514-1531 (2004).

DOI: $10.1002 /$ polb.20025

[8] Chiu H-C., Lin Y-F., Hung S-H.: Equilibrium swelling of copolymerized acrylic acid-methacrylated dextran networks: Effects of $\mathrm{pH}$ and neutral salt. Macromolecules, 35, 5235-5242 (2002).

DOI: $\underline{10.1021 / \mathrm{ma} 0122021}$

[9] Xiao X. C.: Effect of the initiator on thermosensitive rate of poly( $N$-isopropylacrylamide) hydrogels. Express Polymer Letters, 1, 232-235 (2007).

DOI: $10.3144 /$ expresspolymlett.2007.35

[10] Park J. S., Kataoka K.: Precise control of lower critical solution temperature of thermosensitive poly(2-isopropyl-2-oxazoline) via gradient copolymerization with 2-ethyl-2-oxazoline as a hydrophilic comonomer. Macromolecules, 39, 6622-6630 (2006).

DOI: $\underline{10.1021 / \mathrm{ma0605548}}$

[11] Maeda Y.: IR spectroscopic study on the hydration and the phase transition of poly(vinyl methyl ether) in water. Langmuir, 17, 1737-1742 (2001).

DOI: $10.1021 / \mathrm{la001346q}$

[12] Schild H. G.: Poly( $N$-isopropylacrylamide): Experiment, theory and application. Progress in Polymer Science, 17, 163-249 (1992).

DOI: $10.1016 / 0079-6700(92) 90023-\mathrm{R}$

[13] Fundueanu G., Constantin M., Bortolotti F., Cortesi R., Ascenzi P., Menegatti E.: Poly[( $N$-isopropylacrylamide- $c o$-acrylamide- $c o$-(hydroxyethylmethacrylate))] thermoresponsive microspheres: An accurate method based on solute exclusion technique to determine the volume phase transition temperature. European Polymer Journal, 43, 3500-3509 (2007).

DOI: $10.1016 /$ j.eurpolymj.2007.05.026

[14] Lokitz B. S., York A. W., Stempka J. E., Treat N. D., Li Y. T, Jarrett W. L., McCormick C. L.: Aqueous RAFT Synthesis of micelle-forming amphiphilic block copolymers containing $N$-acryloylvaline. Dual mode, temperature/pH responsiveness, and 'locking' of micelle structure through interpolyelectrolyte complexation. Macromolecules, 40, 6473-6480 (2007). DOI: $\underline{10.1021 / \mathrm{ma} 070921 \mathrm{v}}$

[15] Chen J., Sun J., Yang L. M., Zhang Q. F., Zhu H. N., Wu H. F., Hoffman A. S., Kaetsu I.: Preparation and characterization of a novel IPN hydrogel memberane of poly $(N$-isopropylacrylamide)/carboxymethyl chitosan (PNIPAAM/CMCS). Radiation Physics and Chemistry, 76, 1425-1429 (2007).

DOI: $10.1016 /$ j.radphyschem.2007.02.045
[16] Nitschke M., Götze T., Gramm S., Werner C.: Detachment of human endothelial cell sheets from thermoresponsive poly(NiPAAm-co-DEGMA) carriers. Express Polymer Letters, 1, 660-666 (2007).

DOI: $10.3144 /$ expresspolymlett.2007.90

[17] Ivanova P., Eliyas A.: Kinetics of the esterification of methacrylic acid with ethylene oxide in the presence of ferric chloride immobilized on polymer support. Applied Catalysis, 53, 41-52 (1989).

DOI: $10.1016 / \mathrm{S} 0166-9834(00) 80008-1$

[18] Stempel G. H., Cross R. P., Mariella R. P.: The preparation of acrylyl chloride. Journal of the American Chemical Society, 72, 2299-2300 (1950).

DOI: $10.1021 / \mathrm{ja} 01161 \mathrm{a} 527$

[19] Eggenhuisen T. M., Becer C. R., Fijten M. W. M., Eckardt R., Hoogenboom R., Schubert U. S.: Libraries of statistical hydroxypropyl acrylate containing copolymers with LCST properties prepared by NMP. Macromolecules, 41, 5132-5140 (2008). DOI: $\underline{10.1021 / \mathrm{ma} 800469 \mathrm{p}}$

[20] Feil H., Bae Y. H., Feijen J., Kim S. W.: Effect of comonomer hydrophilicity and ionization on the lower critical solution temperature of $\mathrm{N}$-isopropylacrylamide copolymers. Macromolecules, 26, 2496-2500 (1993). DOI: $\underline{10.1021 / \mathrm{ma} 00062 \mathrm{a} 016}$

[21] Liu S. X., Liu M. Z.: Synthesis and characterization of temperature- and $\mathrm{pH}$-sensitive poly $(\mathrm{N}, \mathrm{N}$-diethylacrylamide-co-methacrylic acid). Journal of Applied Polymer Science, 90, 3563-3568 (2003).

DOI: 10.1002/app.13034

[22] Schmitz S., Ritter H.: Unusual solubility properties of polymethacrylamides as a result of supramolecular interactions with cyclodextrin. Angewandte Chemie, International Edition, 44, 5658-5661 (2005).

DOI: 10.1002/anie. 200501374

[23] Von Hippel P. H., Schleich T.: Ion effects on the solution structure of biological macromolecules. Accounts of Chemical Research, 2, 257-265 (1969). DOI: $\underline{10.1021 / \mathrm{ar} 50021 \mathrm{a} 001}$

[24] Nishio Y., Chiba R., Miyashita Y., Oshima K., Miyajama T., Kimura N., Suzuki H.: Salt addition effects on mesophase structure and optical properties of aqueous hydroxypropyl cellulose solutions. Polymer Journal, 34, 149-157 (2002).

DOI: $10.1295 /$ polymj. 34.149

[25] Lee S. B., Song S-C., Jin J-I., Sohn Y. S.: A new class of biodegradable thermosensitive polymers. 2 . Hydrolytic properties and salt effect on the lower critical solution temperature of poly(organophosphazenes) with methoxypoly(ethylene glycol) and amino acid esters as side groups. Macromolecules, 32, 7820-7827 (1999). DOI: $10.1021 / \mathrm{ma} 990645 \mathrm{n}$ 